\title{
On meeting capital requirements with a chance-constrained optimization model
}

\author{
Ebenezer Fiifi Emire Atta Mills', Bo Yu and Lanlan Gu
}

*Correspondence:

attamills2003@gmail.com; attamills@mail.dlut.edu.cn

School of Mathematical

Sciences, Dalian University

of Technology, Dalian 116024 , China

\begin{abstract}
This paper deals with a capital to risk asset ratio chance-constrained optimization model in the presence of loans, treasury bill, fixed assets and non-interest earning assets. To model the dynamics of loans, we introduce a modified CreditMetrics approach. This leads to development of a deterministic convex counterpart of capital to risk asset ratio chance constraint. We pursue the scope of analyzing our model under the worst-case scenario i.e. loan default. The theoretical model is analyzed by applying numerical procedures, in order to administer valuable insights from a financial outlook. Our results suggest that, our capital to risk asset ratio chance-constrained optimization model guarantees banks of meeting capital requirements of Basel III with a likelihood of $95 \%$ irrespective of changes in future market value of assets.
\end{abstract}

Keywords: Capital to risk asset ratio, Basel accord, CreditMetrics, Chance constraint

\section{Background}

The financial crisis of 2008 reaffirmed the need to monitor risk in the banking sector as it has a ripple effect on the overall economy. The insolvency of most financial outfits at that time was as a result of increasing amounts of capital invested into long term and risky assets especially in the real estate market (Cannata and Quagliariello 2009; Brusov et al. 2015). Now more than ever, matters of subprime lending and the relevance of maintaining adequate capital to absorb adverse market conditions have become very important to bank managers and financial regulators (Erkens et al. 2012; Flannery 2014). Policy makers have recommended changes to already existing coordinated regulation to avert the probability of such occurrence in future. These changes include, significant increment in Capital to Risk (Weighted) Assets Ratio (CRAR) which is dependent on both the capital required and the capital resources to meet the requirements (Hasan et al. 2015). As a step in that direction, this paper's primary aim is to use an asset-liability modeling approach via optimization techniques based on the CRAR to guarantee banks of meeting the stipulated regulation of Basel III with great likelihood irrespective of changes in forward market value of assets.

Asset-liability management in the banking sector primarily seeks to maximize profit through high returns on loans and other financial instruments, minimize risk as a result of mismatches between assets and liabilities and provide for liquidity needs (Choudhry 2012). Most banks manage their assets by issuing loans to creditors who have the

(c) 2016 Atta Mills et al. This article is distributed under the terms of the Creative Commons Attribution 4.0 International License (http://creativecommons.org/licenses/by/4.0/), which permits unrestricted use, distribution, and reproduction in any medium, provided you give appropriate credit to the original author(s) and the source, provide a link to the Creative Commons license, and indicate if changes were made. 
capability to pay high interest rates and have minimal probability of default on their loans. Banks also diversify their investment portfolio and invest in securities with high returns and minimal risk in a bid to manage their assets. Over the years, several techniques and tools have been developed to aid bank managers in making the right investment decisions whilst reducing risk (see Szegö 2014; Bessis 2015; McNeil et al. 2015, for detailed reference). Policy makers have designed an internationally coordinated regulation known as the Basel Accord to ensure banks can absorb a reasonable and sufficient level of losses, which might otherwise threaten their solvency (Arnold et al. 2012; Lee 2014). Basel III bolsters and re-evaluates the global capital framework by increasing banks capital to risk (weighted) assets ratio (CRAR) requiring banks to raise capital defenses in times when credit is at excessive levels while upholding a financially sound banking environment which is the foundation of a functional market economy (Leignick and Wohltmann 2015). Banks manage the liquidity of their assets in order to meet reserve requirements such as the Third Basel Accord without incurring high costs.

Berger et al. (2008), Flannery and Rangan (2008) and Gropp and Heider (2010) show that banks CRAR respond to the shocks in the regulatory requirements and that banks actively manage their target capital levels that tend to exceed the minimally required ones. Athanasoglou et al. (2008) iterates the fact that banks with strong financial foundation and position pursue investment opportunities more effectively and have more time and awareness to counter problems such as unexpected losses thus attaining increased profitability. The application of the minimum capital to risk (weighted) assets ratio protects depositors and promotes the stability and efficiency of the financial systems. In their panel regressions on individual bank capital requirements in the UK, Bridges et al. (2014) observed that changes in micro prudential regulatory capital requirements affects capital ratios held by the banks and also affect lending with heterogeneous feedbacks in diverse sectors of the economy. Their finding shows how meeting capital a requirement is an important component of banks asset structure.

In this paper, we propose a chance-constrained optimization model by considering loan distribution follows a right truncated Gaussian distribution, to guarantee banks of coping with Basel III capital requirements even under the worst case scenario. We deal with an optimal portfolio model assuming that loans and a treasury bill are the investments made by the bank. The problem is faced under a theoretical perspective as well as simulation analysis. The introduction of a CRAR constraint characterized by the assumption made on the loan distribution, the construction of the deterministic convex counterpart of the CRAR chance constraint to obtain a tractable linear second order cone constraint and modified CreditMetrics approach represents the main novelty of this research paper.

To achieve our aim, we consider an optimization problem with the chance constraint of capital to risk (weighted) assets ratio under the condition that information regarding the distribution, mean and covariance of the risky asset in this case loan are known. Charnes and Cooper (1996) introduced chance-constrained programs. Over the years, significant literature have been established in this regard (see Prékopa 1995; Uryasev 2000; Delage and Mannor 2010; Barrera et al. 2014, for detailed discussion and applications). In finance and engineering, several problems can and have been constructed as chance-constrained stochastic linear programs of the form 


$$
\begin{aligned}
\underset{x \in \mathbb{R}^{n}}{\operatorname{minimize}} & c^{T} x \\
\text { subject to } & \mathbb{P}\left\{a_{i}(\zeta)^{T} x+b_{i}(\zeta) \leq 0, \forall i=1, \ldots, m\right\} \geq 1-\epsilon_{i} \\
x & \in \chi
\end{aligned}
$$

where $x \in \mathbb{R}^{n}$ is the decision vector(investment allocations) and the uncertain constraint coefficients $a_{i}(\zeta) \in \mathbb{R}^{n}$ and $b_{i}(\zeta) \in \mathbb{R}, \forall i=1, \ldots, m$, depend affinely on random vector $\zeta \in \mathbb{R}^{h+1}$ whose distribution is assumed to be known. $1-\epsilon, \epsilon \in(0,1)$ is the risk level or safety factor usually given by the modeler. We thus have,

$$
\begin{aligned}
& a_{i}(\zeta)=a_{i}^{0}+\sum_{j=1}^{k} a_{i}^{j} \zeta_{j} \\
& b_{i}(\zeta)=b_{i}^{0}+\sum_{j=1}^{k} b_{i}^{j} \zeta_{j}
\end{aligned}
$$

Auxiliary functions $y_{i}^{j}: \mathbb{R}^{n} \rightarrow \mathbb{R}$ are introduced for relaxation of notations and are defined through

$$
y_{i}^{j}(x)=\left(a_{i}^{j}\right)^{T} x+b_{i}^{j}, \quad i=1,2, \ldots, n, \quad j=0,1, \ldots, k
$$

Therefore (1) can be rewritten as

$$
\begin{aligned}
& \mathbb{P}\left(a_{i}^{0^{T}} x+b_{i}^{0}+\sum_{j=1}^{k}{a_{i}^{j}}^{T} \zeta_{j}+b_{i}^{j} \zeta_{j}\right) \leq 0 \\
& \mathbb{P}\left(y_{i}^{0}(x)+\sum_{j=1}^{k} y_{i}^{j}(x) \zeta_{j}\right) \leq 0
\end{aligned}
$$

For tractability purposes, we redefine the chance constraint (1) and rewrite (2) as a single generic constraint (Zymler et al. 2013), i.e. $i=1$ and $k=1$

$$
\mathbb{P}\left\{y^{0}(x)+y(x)^{T} \zeta \leq 0\right\} \geq 1-\epsilon
$$

By doing this, we convert the two uncertain parameters, $a_{i}(\zeta) \in \mathbb{R}^{n}$ and $b_{i}(\zeta) \in \mathbb{R}$ in (1) to one uncertain parameter, $\zeta \in \mathbb{R}^{k}$ in (2). We define the random vector $r=\left[\begin{array}{ll}1 & \zeta^{T}\end{array}\right]^{T} \in \mathbb{R}^{h+1}$ where the first coordinate is a constant random variable and $\zeta$ is defined as forward market loan value which is estimated by modified CreditMetrics approach under a right truncated Gaussian distribution.

We consider all possible credit migration paths as opposed to sample credit migration paths in the CreditMetrics technical document by Gupton et al. (1997) and also make some other modifications. (see "CreditMetrics approach" section and "Appendix"). Luedtke (2014) and Yang and Xu (2016) pointed out that computation of the optimal solution of a chance-constrained program is notably hard to solve. Indeed, the only notable tractable case of the chance constraint formulation is by Calafiore and El Ghaoui's (2006) paper when the chance constraint function is bilinear and the distribution of the uncertain data follows a set of radial probability distributions. Empirical evidence have 
revealed that the normal distribution is not appropriate to estimate credit risk (Crouhy et al. 2010). Returns in the credit markets are heavily skewed to the downside and therefore are non-normal (Gupton et al. 1997). Saunders and Allen (2010) observed that loans have acutely truncated upside returns and long downside risks and that the actual loan portfolio value distribution has negative skewness or a long-tailed downside. In this paper, we make an informed decision on the random vector $r$ based on Saunders and Allen's (2010) view on the actual loan portfolio distribution and assume that loan distribution can be described by truncated Gaussian distribution. One possible extension would be to consider, instead of truncated Gaussian distributed returns, the more general alpha-stable distributed returns (see (Rachev 2003; Rachev et al. 2005)).

The paper is organized as follows. Next section evaluates the probability constraint for right truncated Gaussian probability distribution and construct the deterministic convex counterpart of the chance constraint. The next section presents the CreditMetrics approach to estimate the forward market value of loans. The formulation of the optimization model based on the chance constraint of CRAR is structured and presented. We conduct a numerical example and illustrate the proposed method by a hypothetical example. Results and Concluding remarks are presented in the last section. Details and pseudocodes of the numerical procedure described in "CreditMetrics approach" section are given in "Appendix".

\section{Chance constraint under truncated Gaussian distribution}

Inspired by Calafiore (2006), we discuss a facet of the chance-constrained stochastic program (1). We evaluate the probability constraint for right truncated Gaussian probability distribution and construct specifically the deterministic convex counterpart of the chance constraint.

\section{Notation and parameter description}

Without loss of generality, based on a standing assumption that the random constraints in (2) are independent, we make use of the single generic constraint

$$
\mathbb{P}\left\{y^{0}(x)+y(x)^{T} \zeta \leq 0\right\} \geq 1-\epsilon, \epsilon \in(0,1)
$$

and define the random vector

$$
r=\left[\begin{array}{ll}
1 & \zeta^{T}
\end{array}\right]^{T} \in \mathbb{R}^{h+1}
$$

and

$$
\begin{aligned}
& \hat{r}=E\{r\}=E\left\{\left[\begin{array}{ll}
1 & \zeta^{T}
\end{array}\right]^{T}\right\}=\left[\begin{array}{ll}
1 & \hat{\zeta}^{T}
\end{array}\right]^{T} \\
& \Gamma=\operatorname{var}\{r\}=\operatorname{var}\left\{\left[\begin{array}{ll}
1 & \zeta^{T}
\end{array}\right]\right\}
\end{aligned}
$$

Consider $v \leq h+1$ as the rank of $\Gamma$ and $\Gamma_{f . r} \in \mathbb{R}^{h+1}$ as a full rank factor such that $\Gamma=\Gamma_{f . r} \Gamma_{f . r}^{T}$. Let

$$
\tilde{z}=\left[\begin{array}{ll}
y^{0}(x) & y(x)^{T}
\end{array}\right]^{T} \in \mathbb{R}^{h+1}
$$


We define the quantity

$$
\varphi(z)=r^{T} \tilde{z}
$$

and

$$
\begin{aligned}
& \hat{\varphi}(z)=E\{\varphi(z)\} \\
& \sigma^{2}(z)=\operatorname{var}\{\varphi(z)\}=\tilde{z}^{T} \Gamma \tilde{z}
\end{aligned}
$$

The normalized random variable is defined as

$$
\hat{\varphi}(z)=\frac{\varphi(z)-\hat{\varphi}(z)}{\sigma(z)}
$$

Therefore, we can rewrite constraint (3) as

$$
\mathbb{P}\{\varphi(z) \leq 0\}=\mathbb{P}\{\tilde{\varphi}(z) \leq-\hat{\varphi}(z) / \sigma(z)\} \geq 1-\epsilon
$$

\section{Formulation}

Definition 1 A random vector $r \in \mathbb{R}^{h+1}$ is $Y$-radial with defining function $g(\cdot)$ if $r-E(r)=Y \eta$ where $Y \in \mathbb{R}^{h+1, v}$ is a full rank matrix of a fixed nature and $\eta \in \mathbb{R}^{v}$ is a random vector with probability density function $f_{\eta}$ that is dependent exclusively on the norm of $\eta$ i.e. $f_{\eta}(\eta)=g(\|\eta\|)$.

From the above definition, the covariance of $\eta$ is

$$
\Sigma_{\eta}=\left(V_{v} \int_{0}^{\infty} w^{v+1} g(w) d w\right) I_{v}
$$

where $V_{\nu}$ is the Euclidean volume of the standard unit ball of radius $\mathbb{R}^{v}$. The variance of $r$ is defined as

$$
\operatorname{var}\{r\}=\left(V_{v} \int_{0}^{\infty} w^{v+1} g(w) d w\right) Q Q^{T}
$$

Given that $\operatorname{var}\{r\}=\Gamma$, then $Y=s \Gamma_{f . r}, \quad s=\left(V_{v} \int_{0}^{\infty} w^{v+1} g(w) d w\right)^{-1 / 2}$ where $\Gamma_{f . r}$ is a full rank factor of $\Gamma$ i.e. $\Gamma=\Gamma_{f . r} \Gamma_{f . r}^{T}$. The possibly singular multivariate $b$ right truncated Gaussian distribution in $\mathbb{R}^{h+1}$, with mean $\tilde{r}$ and covariance $\Gamma$ is $Y$-radial with $Y=s \Gamma_{f . r}$ and defining function

$$
g(w)=\frac{1}{\left\{\sigma \Phi\left(\frac{b-\mu}{\sigma}\right)\right\}^{s}} \phi\left(\frac{w-\mu}{\sigma}\right)
$$

If $r$ is $Y$-radial and has defining function $g(w)$ and covariance $\Gamma$, then

$$
\begin{aligned}
\tilde{\varphi}(z) & =\tilde{z} Y \eta / \sigma(z)=s \tilde{z}^{T} \Gamma_{f . r} \eta / \sqrt{\tilde{z}^{T} \tilde{z}} \\
\mathbb{P}\{\varphi(z) \leq 0\} & =\mathbb{P}\{\tilde{\varphi}(z) / s \leq-\hat{\varphi}(z) / s \sigma(z)\}=\mathbf{F}_{\tilde{\varphi}(z) / s}(-\hat{\varphi}(z) / s \sigma(z))
\end{aligned}
$$

and the cumulative density function is defined as 


$$
\mathbf{F}_{\tilde{\varphi}(z) / s}(-\hat{\varphi}(z) / s \sigma(z))=\int_{-\infty}^{-\hat{\varphi}(z) / s \sigma(z)} f_{\tilde{\varphi}(z) / s}(L) d L
$$

Therefore, $\mathbb{P}\{\varphi(z) \leq 0\} \geq 1-\epsilon$ is equivalent to $s \mathbf{F}^{-1}(1-\epsilon) \sigma(z)+\hat{\varphi}(z) \leq 0$ for $\epsilon \in(0,1)$.

A $b$ right truncated Gaussian distribution with covariance $\Gamma$ and mean $\hat{r}$ is $Y$-radial with $Y=\Gamma_{f . r}, s=1$ and defining function

$$
g(w)=\frac{1}{\sigma \Phi\left(\frac{b-\mu}{\sigma}\right)} \phi\left(\frac{w-\mu}{\sigma}\right)
$$

Appropriately, $f_{\tilde{\varphi}(z) / s}$ is the $b$ right truncated Gaussian density function

$$
f_{\tilde{\varphi}(z) / s}(L)=\frac{1}{\sigma \Phi\left(\frac{b-\mu}{\sigma}\right)} \phi\left(\frac{L-\mu}{\sigma}\right)
$$

and $\mathbf{F}$ is the standard $b$ right truncated Gaussian distribution cumulative probability function

$$
\mathbf{F}(L)=\mathbf{F}_{R G}(L)=\int_{-\infty}^{L} \frac{1}{\Phi(b)} \phi(t) d t=\frac{1}{\Phi(b)} \Phi(L)
$$

and the inverse for the standard $b$ right truncated Gaussian distribution cumulative probability function is

$$
\mathbf{F}^{-1}(L)=\mathbf{F}_{R G}^{-1}(L)=\Phi^{-1}(\Phi(b) \cdot L)
$$

Theorem 1 The chance constraint, $\mathbb{P}\left\{\hat{r}^{T} \tilde{z} \leq 0\right\} \geq 1-\epsilon$, for any $\epsilon \in(0,1)$ where $r$ has $a b$ right truncated Gaussian distribution with defining function $g(w)$, covariance $\Gamma$ and mean $\hat{r}$ with $s=1$ is equivalent to the second order cone (SOC) constraint $\mathbf{F}_{R G}^{-1}(1-\epsilon) \sqrt{\tilde{z} \Gamma \tilde{z}}+\hat{r}^{T} \tilde{z} \leq 0$.

\section{CreditMetrics approach}

Future bank capital is dependent on the forward market values of assets as well as liabilities. We use a modified CreditMetrics approach to estimate the forward market value of loans which is the uncertainty parameter in (3). CreditMetrics from JP Morgan, made public and published in 1997, is reviewed in this section. The methodology estimates the forward distribution of the changes in portfolio value of loan products at a specified time horizon, typically one year. The changes in value are associated with the migration in credit quality of the obligor, both up and downgrades, including default. We develop a Monte Carlo framework from a modified CreditMetrics approach (see "Appendix") to include all possible migrations and scenarios. This method is adopted for the purpose of calculating the forward market value of loans and its associated risk measure. 


\section{Rating migration}

Based on historical data on loan, Standard and Poor (S\&P) construct a transition matrix which shows the probability of a rated loan being downgraded, upgraded or defaulting during a given period, usually one year. The estimated probabilities of average one-year corporate transition rates (1981-2013) of corporations based in Europe are shown in Table 1. Each cell in the transition matrix has a probability. The rating sections in the rows of the transition matrix signify current credit ratings and the columns of the transition matrix show expected credit rating at the end of the year. For example, the $P(B B B \rightarrow B B)=0.0431$ show the chances of a $B B B$-rated loan downgrading to $\mathrm{B}$ over the ensuing year.

Recovery rates and the probability of default are essential parameters in credit risk modeling. Calabrese (2008) defines recovery rate as the payback quota of the loan. Considerable studies on recovery rates on corporate bonds have been performed (Altman 1989; Schuermann 2004; Renault and Scaillet 2004; Jankowitsch et al. 2014) and Asarnow and Edwards (1995), Calabrese and Zenga (2008), Khieu et al. (2012) and Calabrese (2008) have all investigated bank loans. Carty and Lieberman (1996) and Schuermann (2004) made an interesting revelation by showing that the mean of bonds is lower than the average recovery rate of bank loans. Calabrese and Zenga (2008) measured the recovery rates on non-performing bank loans in Italy by using the boundary property $[0,1]$ in computing the loan recovery rate as the ratio between capitalized actual recovery amount and capitalized total exposure, where the latter parameter is the sum of Exposure-At-Default , capitalized legal costs and interest on delayed payment. We employ loan recovery rates estimated in Calabrese and Zenga (2008) for Italy under categories of secured and unsecured loans shown in Table 2 for the estimation of forward value of loans via a modified CreditMetrics approach.

Table 1 Average 1-year corporate transition rates for Europe (1981-2013) (\%). Source: Standard \& Poor's Annual Global Corporate Default Study \& Rating Transitions (March 2014)

\begin{tabular}{lrrrrrrrrr}
\hline RATING & AAA & \multicolumn{1}{c}{ AA } & \multicolumn{1}{c}{ A } & BBB & BB & \multicolumn{1}{c}{ B } & CCC/C & D & Not rated \\
\hline AAA & 83.12 & 10.76 & 0.63 & 0.21 & 0.00 & 0.00 & 0.21 & 0.00 & 5.06 \\
AA & 0.28 & 84.32 & 10.92 & 0.66 & 0.00 & 0.00 & 0.00 & 0.00 & 3.81 \\
A & 0.02 & 2.17 & 85.95 & 6.36 & 0.24 & 0.02 & 0.00 & 0.05 & 5.20 \\
BBB & 0.00 & 0.12 & 4.26 & 82.99 & 4.31 & 0.50 & 0.12 & 0.10 & 7.70 \\
BB & 0.00 & 0.00 & 0.13 & 4.92 & 71.46 & 8.02 & 0.57 & 0.57 & 14.33 \\
B & 0.00 & 0.00 & 0.07 & 0.49 & 7.52 & 68.31 & 4.85 & 3.30 & 15.46 \\
CCC/C & 0.00 & 0.00 & 0.00 & 0.00 & 0.00 & 16.22 & 31.76 & 31.76 & 20.27 \\
\hline
\end{tabular}

Table 2 Loan recovery rates of Italy by secured status (\%). Source: Calabrese and Zenga (2008)

\begin{tabular}{lll}
\hline Status & Secured & Unsecured \\
\hline Mean & 56.66 & 37.98 \\
Standard deviation & 30.44 & 33.87 \\
\hline
\end{tabular}




\section{Valuation}

In this section, we calculate forward value of loans at the end of the risk horizon, 1 year. However, since there are 8 possible credit ratings in the transition matrix from Table 1 , we have to estimate values based on all possible migration paths given maturity dates. In the worst case scenario of the loan i.e. default, two input variables are required the secured status of the loan and its associated recovery rate.

Valuation is done based on all the possible migration paths, residual cash flows and from the one-year forward zero-curve associated with the rating of the issuer. Expected upgrade or downgrade in credit rating leads to changes in the value of the loan. The magnitude of these changes are accessible with the estimation of forward zero curves for each rating Abaffy et al. (2007).

From Table $3, f_{c r}^{1, j}$ is the $(j-1)$-year forward rate with credit rating $c r$ thus for year 1 , we have $f_{c r}^{1,2}$ and so on. By this interpretation, the entries of Table 3 are spot rates from now. Consider $\tilde{f}_{c r}^{i, i+1}$ as the one-year forward rate with its associated credit rating $c r_{i}$ from the end of the $i$-th year to the end of the $(i+1)$-th year. Therefore, the one-year forward rate can be estimated by

$$
\begin{aligned}
\tilde{f}_{c r_{1}}^{1,2}=f_{c r_{1}}^{1,2}, \quad i & =1 \\
\left(1+f_{c r_{i}}^{i, i+1}\right)^{i} & =\left(1+\tilde{f}_{c r_{i}}^{i, i+1}\right)\left(1+f_{c r_{i}}^{1, i}\right)^{i-1}, \quad i=2, \ldots, m-1
\end{aligned}
$$

The discount factor of the cash flow from the end of the $j$ th year to the end of the first year for loan type $k$ can be computed by the following

$$
\begin{aligned}
& d_{k 1}^{-1}=1, \quad j=1 \\
& d_{k j}^{-1}=\prod_{i=1}^{j-1}\left(1+\tilde{f}_{c r_{i}}^{i, i+1}\right)=\prod_{i=1}^{j-1} \frac{\left(1+f_{c r_{i}}^{i, i+1}\right)^{i}}{\left(1+f_{c r_{i}}^{1, i}\right)^{i-1}}, \quad j=2, \ldots, m
\end{aligned}
$$

The forward loan value is the sum of discounted cash flows of each year corresponding to possible credit rating transition paths till maturity $m$. Then the forward value, $\zeta_{k t}$ of a unit capital invested in the $k$ th loan with a non-default credit rating migration path $t$ is

$$
\zeta_{k t}=\sum_{j=1}^{m-1} R_{k} d_{k j}+\left(1+R_{k}\right) d_{k m}
$$

where $R_{k}$ is the interest rate of the $k$ th loan.

Table 3 One-year forward zero curve for each credit rating category (\%). Source: CreditMetrics, JP Morgan

\begin{tabular}{lcccc}
\hline Category & Year $\mathbf{1}\left(\boldsymbol{f}_{\boldsymbol{c r}}^{\mathbf{1}, \mathbf{2}}\right)$ & Year $\mathbf{2}\left(\boldsymbol{f}_{\boldsymbol{c r}}^{\mathbf{1 , \mathbf { 3 }}}\right)$ & Year $\mathbf{3}\left(\boldsymbol{f}_{\boldsymbol{c r}}^{\mathbf{1}, \mathbf{4}}\right)$ & Year 4 $\left(\boldsymbol{f}_{\boldsymbol{c r}}^{\mathbf{1 , 5}}\right)$ \\
\hline AAA & 3.60 & 4.17 & 4.73 & 5.12 \\
AA & 3.65 & 4.22 & 4.78 & 5.17 \\
A & 3.72 & 4.32 & 4.93 & 5.32 \\
BBB & 4.10 & 4.67 & 5.25 & 5.63 \\
BB & 5.55 & 6.02 & 6.78 & 7.27 \\
B & 6.05 & 7.02 & 8.03 & 8.52 \\
CCC/C & 15.05 & 15.02 & 14.03 & 13.52 \\
\hline
\end{tabular}


In case $k$ th loan defaults before or at the end of the period $q=1,2,3, \ldots, m$, then the forward value, $\zeta_{k d t}$, of a unit capital invested in the $k$ th loan with a default credit rating migration path $d t$ is

$$
\zeta_{k d t}=\sum_{j=1}^{q-1} R_{k} d_{k j}+R R_{k} d_{k m}
$$

where $R R_{k}$ is the recovery rate if the $k$ th loan which is dependent on the secured status in Table 2.

Table 4 shows the possible migration paths for a 2 year BBB-rated loan. There are 49 non-default paths and 8 default paths. In general, the $k$ th loan with maturity $m$ has $7^{m}$ non-default possible credit rating migration paths. The $k$ th loan with maturity $m$ has $\sum_{q=1}^{m} 7^{q-1}$ default possible credit rating migration paths.

\section{Expected value and credit risk}

Gupton et al. (1997) and Benz (2002) observed that credit returns are heavily skewed to the downside and therefore are non-normal. Saunders and Allen (2010) also made an interesting revelation that loans have both acutely truncated upside returns and also long downside risks and that the actual loan portfolio value distribution exhibits a long-tailed downside or negative skewness. We therefore make an informed decision based on empirical evidence on the actual loan portfolio distribution and assume that the $k$ th loan year-ahead or forward value, $\zeta_{k}$, distribution is described by the right truncated Gaussian distribution. The long downside tail of the distribution of loan returns is caused by defaults.

Consider the credit migration path satisfying the Markov property, then the migration probability of the $k$ th loan with $t$ non-default path is

$$
P_{k t}=\prod_{i=0}^{m-1} P_{c r_{i}, c r_{i+1}}, \quad t=1, \ldots, 7^{m}
$$

and for default path

$$
P_{k d t}=\prod_{i=0}^{q-1} P_{c r_{i}, c r_{i+1}}, \quad t=1, \ldots, N \quad N=\sum_{q=1}^{m} 7^{q-1}
$$

where $P_{c r_{i}, c r_{i+1}}$ signify the probability of migration from $c r_{i}$ credit rating at the end of the $i$ th year to $c r_{i+1}$ credit rating at the end of $(i+1)$-th year.

By the assumption of the forward loan value of unit capital invested in the $k$ th loan following a right truncated Gaussian distribution at $b$, then the expected forward loan (mean) value and variance of unit capital invested in the $k$ th loan are

$$
E\left(\zeta_{k} \mid \zeta_{k} \leq b\right)=\mu_{k}-\sigma_{k}\left[\frac{\phi(\beta)}{\Phi(\beta)}\right], \quad \mu_{k}=\sum_{t=1}^{7^{m}} \zeta_{k t} P_{k t}+\sum_{t=1}^{N} \zeta_{k d t} P_{k d t}
$$


Table 4 Possible migration paths of a 2 year BBB-rated loan

\begin{tabular}{|c|c|c|c|c|c|c|c|}
\hline & $\begin{array}{l}\text { Non-default } \\
\mathrm{m}=0\end{array}$ & $\begin{array}{l}\text { Migration } \\
\mathrm{m}=1\end{array}$ & $\begin{array}{l}\text { Paths } \\
m=2\end{array}$ & & $\begin{array}{l}\text { Default } \\
m=0\end{array}$ & $\begin{array}{l}\text { Migration } \\
\mathrm{m}=1\end{array}$ & $\begin{array}{c}\text { Paths } \\
\mathrm{m}=2\end{array}$ \\
\hline 1 & $\mathrm{BBB}$ & AAA & AAA & 1 & $\mathrm{BBB}$ & $D$ & \\
\hline 2 & BBB & AAA & $\mathrm{AA}$ & 2 & BBB & AAA & $D$ \\
\hline 3 & BBB & AAA & A & 3 & BBB & $\mathrm{AA}$ & $D$ \\
\hline 4 & BBB & AAA & BBB & 4 & BBB & A & D \\
\hline 5 & BBB & AAA & $\mathrm{BB}$ & 5 & BBB & BBB & $D$ \\
\hline 6 & BBB & AAA & B & 6 & BBB & BB & $D$ \\
\hline 7 & BBB & AAA & $C$ & 7 & BBB & B & $D$ \\
\hline 8 & BBB & $\mathrm{AA}$ & AAA & 8 & BBB & C & $D$ \\
\hline 9 & BBB & $\mathrm{AA}$ & $\mathrm{AA}$ & & & & \\
\hline 10 & BBB & $\mathrm{AA}$ & A & & & & \\
\hline 11 & BBB & $\mathrm{AA}$ & BBB & & & & \\
\hline 12 & BBB & $\mathrm{AA}$ & $\mathrm{BB}$ & & & & \\
\hline 13 & BBB & $\mathrm{AA}$ & $B$ & & & & \\
\hline 14 & BBB & $\mathrm{AA}$ & C & & & & \\
\hline 15 & BBB & A & AAA & & & & \\
\hline 16 & BBB & A & $\mathrm{AA}$ & & & & \\
\hline 17 & BBB & A & A & & & & \\
\hline 18 & BBB & A & BBB & & & & \\
\hline 19 & BBB & A & $\mathrm{BB}$ & & & & \\
\hline 20 & BBB & A & B & & & & \\
\hline 21 & BBB & A & C & & & & \\
\hline 22 & BBB & BBB & AAA & & & & \\
\hline 23 & BBB & BBB & $\mathrm{AA}$ & & & & \\
\hline 24 & BBB & BBB & A & & & & \\
\hline 25 & BBB & BBB & BBB & & & & \\
\hline 26 & BBB & BBB & BB & & & & \\
\hline 27 & BBB & BBB & B & & & & \\
\hline 28 & BBB & BBB & C & & & & \\
\hline 29 & BBB & $\mathrm{BB}$ & AAA & & & & \\
\hline 30 & BBB & BB & AA & & & & \\
\hline 31 & BBB & BB & A & & & & \\
\hline 32 & BBB & BB & BBB & & & & \\
\hline 33 & BBB & BB & $\mathrm{BB}$ & & & & \\
\hline 34 & BBB & BB & $B$ & & & & \\
\hline 35 & BBB & BB & $C$ & & & & \\
\hline 36 & BBB & $B$ & AAA & & & & \\
\hline 37 & BBB & B & $\mathrm{AA}$ & & & & \\
\hline 38 & BBB & B & A & & & & \\
\hline 39 & BBB & B & BBB & & & & \\
\hline 40 & BBB & B & BB & & & & \\
\hline 41 & BBB & B & $B$ & & & & \\
\hline 42 & BBB & B & $C$ & & & & \\
\hline 43 & BBB & C & AAA & & & & \\
\hline 44 & BBB & C & $\mathrm{AA}$ & & & & \\
\hline 45 & BBB & C & $A$ & & & & \\
\hline 46 & BBB & C & BBB & & & & \\
\hline 47 & BBB & C & $\mathrm{BB}$ & & & & \\
\hline 48 & BBB & C & $B$ & & & & \\
\hline 49 & BBB & C & C & & & & \\
\hline
\end{tabular}




$$
\begin{aligned}
& \operatorname{Var}\left(\zeta_{k} \mid \zeta_{k} \leq b\right)=\sigma_{k}^{2}\left[1-\beta \frac{\phi(\beta)}{\Phi(\beta)}-\left(\frac{\phi(\beta)}{\Phi(\beta)}\right)^{2}\right], \quad \sigma_{k}^{2}=\sum_{t=1}^{7^{m}}\left(\zeta_{k t}-\mu_{k}\right)^{2} P_{k t} \\
& \quad+\sum_{t=1}^{N}\left(\zeta_{k d t}-\mu_{k}\right)^{2} P_{k d t}
\end{aligned}
$$

respectively.

\section{Formulation of the model}

The optimization model based on the chance constraint of capital to risk (weighted) asset requirement is structured and presented in this section. We first determine the objective function and then proceed to construct its related constraints.

\section{Objective function}

Let $R=\left[R_{1}, R_{2}, \ldots, R_{u}, R_{u+1}, \ldots, R_{u+v}\right]^{T}$ be the vector of annual interest rate of loans and treasury bill, fixed assets and non-interest earning assets (riskless) with $u$ corresponding to the loans and $v$ as the riskless assets. Denote $x=\left[x_{1}, x_{2}, \ldots, x_{u}, x_{u+1}, \ldots, x_{u+v}\right]^{T}$ as the vector of asset allocation or investment proportion which is the decision variable. Then the objective function can be defined as

$$
\max _{x} R^{T} x
$$

\section{Constraints}

\section{CRAR constraint}

Denote $\mathrm{Q}$ as the bank's total asset amount and $T L$ be the bank's total liability. Let $\Omega=\left[\zeta^{T}, \xi^{T}\right]^{T}$ be a unit vector of assets with $\zeta=\left[\zeta_{1}, \zeta_{2}, \ldots, \zeta_{u}\right]^{T}$ and $\xi=\left[\xi_{1}, \xi_{2}, \ldots, \xi_{v}\right]^{T}$ corresponding to loans and riskless assets (treasury bill, fixed assets and non-interest earning assets) respectively. $\zeta$ constitutes uncertain parameters which can be estimated (see "Valuation" section) and $\xi$ is a deterministic vector of $\left[1+R_{u+1}, 1+R_{u+2}, \ldots, 1+R_{u+v}\right]^{T}$. Let $\varpi_{k}$ denote the $k$ th asset's weight factor and $1-\epsilon$ is the safety factor.

According to Basel III, the minimum total capital requirement is $8 \%$. Basel III introduced two additional capital buffers; capital conservation buffer and countercyclical buffer. Capital conservation buffer of $2.5 \%$ is designed to ensure that banks build up capital buffers outside periods of stress which can be drawn down as losses are incurred. The countercyclical buffer range of 0 to $2.5 \%$ which is set by national regulators aims to ensure that banking sector capital requirements take account of the macro-financial environment in which banks operate.

Based on the definition of CRAR i.e.

$$
C R A R=\frac{Q \Omega^{T} x-T L}{Q\left(\varpi_{1} \zeta_{1} x_{1}+\ldots+\varpi_{u} \zeta_{u} x_{u}+\varpi_{u+1} \xi_{u+1} x_{u+1}+\ldots+\varpi_{u+v} \xi_{u+v} x_{u+v}\right)} \geq \lambda
$$

the following holds

$$
\mathbb{P}\left(\frac{Q \Omega^{T} x-T L}{Q\left(\varpi_{1} \zeta_{1} x_{1}+\ldots+\varpi_{u} \zeta_{u} x_{u}+\varpi_{u+1} \xi_{u+1} x_{u+1}+\ldots+\varpi_{u+\nu} \xi_{u+v} x_{u+v}\right)} \geq \lambda\right) \geq 1-\epsilon
$$


As the moment information (mean and variance) of the forward or year-ahead value of $\zeta$ corresponds to all the possible migration paths of loans credit ratings, constraint (16) means even with the changes in the risky assets credit ratings, the bank can still meet the total requirements of the third Basel Accord with greater likelihood. The chance-constrained model based on capital adequacy ratio (16) can be written in terms of a single generic constraint as

$$
\mathbb{P}\left\{y^{0}(x)+y(x)^{T} \zeta \leq 0\right\} \geq 1-\epsilon
$$

where

$$
\begin{aligned}
& y^{0}(x)=T L-Q \sum_{k=u+1}^{u+v}\left(1+R_{k}\right) x_{k} \\
& y(x)=Q \sum_{k=1}^{u}\left(\lambda \varpi_{k}-1\right) x_{k}
\end{aligned}
$$

Proof From the definition of CRAR i.e.

$$
\frac{Q \Omega^{T} x-T L}{Q\left(\varpi_{1} \zeta_{1} x_{1}+\ldots+\varpi_{u} \zeta_{u} x_{u}+\varpi_{u+1} \xi_{u+1} x_{u+1}+\ldots+\varpi_{u+v} \xi_{u+v} x_{u+v}\right)} \geq \lambda
$$

where the riskless asset weight factor is zero i.e. $\sum_{k=u+1}^{u+v} \varpi_{k}=0$, therefore the following holds

$$
\begin{aligned}
& Q \Omega^{T} x-T L \geq \lambda Q\left(\sum_{k=1}^{u} \varpi_{k} \zeta_{k} x_{k}\right) \\
& Q \sum_{k=1}^{u} \zeta_{k} x_{k}+Q \sum_{k=u+1}^{u+v} x_{k}+Q \sum_{k=u+1}^{u+v} R_{k} x_{k}-T L-\lambda Q\left(\sum_{k=1}^{u} \varpi_{k} \zeta_{k} x_{k}\right) \geq 0 \\
& -Q \sum_{k=1}^{u} \zeta_{k} x_{k}-Q \sum_{k=u+1}^{u+v} x_{k}-Q \sum_{k=u+1}^{u+v} R_{k} x_{k}+T L+\lambda Q\left(\sum_{k=1}^{u} \varpi_{k} \zeta_{k} x_{k}\right) \leq 0 \\
& T L+Q \sum_{k=1}^{u}\left(\lambda \varpi_{k}-1\right) \zeta_{k} x_{k}-Q \sum_{k=u+1}^{u+v}\left(1+R_{k}\right) x_{k} \leq 0 \\
& T L-Q \sum_{k=u+1}^{u+v}\left(1+R_{k}\right) x_{k}+Q \sum_{k=1}^{u}\left(\lambda \varpi_{k}-1\right) \zeta_{k} x_{k} \leq 0,
\end{aligned}
$$

which was set out to proof.

Proposition 1 From the mathematical formulation in the "Notation and parameter description" section, under the assumption of known distribution of $r$ as truncated Gaussian distribution, for any $\epsilon \in(0,1)$, constraint (17) is equivalent to $\mathbf{F}_{R G}^{-1}(1-\epsilon) \sigma(\varphi(z))+\hat{\varphi}(z) \leq 0$. 


\section{Constraint based on other factors}

Other constraints to control banks liquidity risk as well as other constraints coping with the defined goals of the bank are constructed here. We assume the set of admissible assets is a nonempty polyhedral set and denote it as $\mathcal{X}=\{x: B x=f, G x=h\}$ where $B$ is a $m \times n$ matrix, $f$ is a $m$-dimensional vector, $G$ is a $p \times n$ matrix and $h$ is a $p$-dimensional vector. In particular, one of the constraints in the set $\mathcal{X}$ is

$$
\sum_{k=1}^{u+v} x_{k}=1
$$

which satisfies the requirements of the sum of all investment allocations to be 1 . Other constraints can be constructed based on the requirement of setting up limit allocation ratio of the investment.

\section{The optimization model}

The asset-liability model via optimization techniques based on the capital asset to risk (weighted) ratio (CRAR) to guarantee banks of coping with the stipulated regulation of Basel III with great likelihood irrespective of changes in forward market value of assets is defined as

$$
\begin{array}{ll}
\underset{x \in \mathbb{R}^{n}}{\operatorname{maximize}} & R^{T} x \\
\text { subject to } & \mathbf{F}_{R G}^{-1}(1-\epsilon) \sigma(\varphi(z))+\hat{\varphi}(z) \leq 0 \\
& \sum_{k=1}^{u+v} x_{k}=1 \\
& x_{1}, x_{2}, \ldots, x_{u+v} \geq 0
\end{array}
$$

Therefore, the CRAR chance-constrained asset-liabilty optimization model based on the informed assumption and decision that the uncertain parameter , $\zeta$ (forward value of a loan) can be described by a $b$ right truncated Gaussian distribution transforms to a tractable second-order cone program (SOCP), which has a solution in polynomial time, refer to Alizadeh and Goldfarb (2003) and Maggioni et al. (2009).

\section{Numerical example}

In this section we test the capability of CRAR chance-constrained asset-liability optimization model on a hypothetical bank operating from Italy. Loan information are somewhat private information. We therefore use datasets with an informed suppositional background. We define and back the data used for the experiment with references and trusted sources.

\section{Data description}

From the asset structure of a bank operating from Italy, let $Q$ the bank's total asset amount be $€ 1500000$ and the bank's total liability TL equal $€ 1192000$. The financial assets characterizing financial environment on the bank are 5 loan types, a treasury bill, fixed assets and non-interest earning assets. We treat treasury bill, fixed assets and non-interest earning assets as riskless assets and the 5 loan types as risky assets. Table 6 shows all necessary information about the financial assets including investment proportions to be allocated. 
The expected forward or year-ahead market value of loan types (13) and its variance (14) are estimated with consideration of all possible migration paths including default.

Interest rate $(R)$ for individual loans are set to lending interest rates for Italy quoted by World Bank in 2013 as a reference point. The treasury bill rate of $0.8 \%$ for Italy in 2013 was also provided by World Bank and risk weights are based on the standardized approach (credit risk) of Basel Accord. The recovery rates for loan types are set according to their collateral status shown in Table 2.

Suppose the correlation coefficent of loans is between $10 \%$ and $30 \%$, with the aid of Table 11.2 in Gupton et al's (1997) CreditMetrics technical document we consider the correlations among loan borrowers as shown Table 5 .

\section{The CRAR chance constraint optimization model}

In this section we present the CRAR chance constraint optimization model. In order to fully understand the model, mathematical computations are made in that regard to obtain a tractable linear SOCP problem.

Table 5 Asset correlations among loans

\begin{tabular}{llllll}
\hline Risky assets & $\zeta_{1}$ & $\zeta_{2}$ & $\zeta_{3}$ & $\zeta_{4}$ & $\zeta_{5}$ \\
\hline$\zeta_{1}$ & 1 & 0.15 & 0.1 & 0.1 & 0.1 \\
$\zeta_{2}$ & 0.15 & 1 & 0.2 & 0.15 & 0.1 \\
$\zeta_{3}$ & 0.1 & 0.2 & 1 & 0.2 & 0.1 \\
$\zeta_{4}$ & 0.1 & 0.15 & 0.2 & 1 & 0.25 \\
$\zeta_{5}$ & 0.1 & 0.1 & 0.1 & 0.25 & 1 \\
\hline
\end{tabular}

Table 6 Asset Structure of an Italian Bank

\begin{tabular}{|c|c|c|c|c|c|c|c|}
\hline Assets & $\begin{array}{l}\text { Collateral } \\
\text { status }\end{array}$ & $\begin{array}{l}\text { Interest } \\
\text { rate }(\%)\end{array}$ & $\begin{array}{l}\text { Recovery } \\
\text { rate }(\%)\end{array}$ & $\begin{array}{l}\text { Risk } \\
\text { weights (\%) }\end{array}$ & Mean & Variance & Allocation \\
\hline $\begin{array}{l}\left(\zeta_{1}\right) 3 \text { year } \\
\text { AAA com- } \\
\text { mercial and } \\
\text { industrial } \\
\text { loan }\end{array}$ & $\begin{array}{l}\text { Inventory or } \\
\text { account } \\
\text { receivables }\end{array}$ & 4.98 & 56.66 & 20 & 0.9143 & 0.0196 & 0.0010 \\
\hline $\begin{array}{l}\left(\zeta_{2}\right) 5 \text { year AA } \\
\text { agriculture } \\
\text { and farm } \\
\text { loan }\end{array}$ & $\begin{array}{l}\text { Land, equip- } \\
\text { ment, crops, } \\
\text { livestock etc }\end{array}$ & 5.71 & 56.66 & 50 & 0.8696 & 0.0347 & 0.1664 \\
\hline $\begin{array}{l}\left(\zeta_{3}\right) 2 \text { year BBB } \\
\text { personal } \\
\text { loan }\end{array}$ & Unsecured & 6.51 & 37.98 & 75 & 0.9247 & 0.0233 & 0.1121 \\
\hline $\begin{array}{l}\left(\zeta_{4}\right) 3 \text { year B } \\
\text { education } \\
\text { loan }\end{array}$ & House, land etc & 5.87 & 56.66 & 75 & 0.6215 & 0.0929 & 0.4192 \\
\hline $\begin{array}{l}\left(\zeta_{5}\right) 4 \text { year } A \\
\text { vehicle loan }\end{array}$ & $\begin{array}{l}\text { Savings account } \\
\text { or car itself }\end{array}$ & 5.14 & 56.66 & 75 & 0.8451 & 0.0360 & 0.2912 \\
\hline $\begin{array}{l}1 \text { year treasury } \\
\text { bill }\end{array}$ & Not applicable & 0.8 & 100 & 0 & 1.008 & 0 & 0.0101 \\
\hline Fixed assets & Not applicable & 0 & 100 & 0 & 1 & 0 & \\
\hline $\begin{array}{l}\text { Non-interest } \\
\text { earning } \\
\text { assets }\end{array}$ & Not applicable & 0 & 100 & 0 & 1 & 0 & \\
\hline
\end{tabular}




\section{Objective function}

Equation (15) is filled with entries of interest rate column of Table 6. Thus,

$$
\underset{x}{\operatorname{maximize}} 0.0498 x_{1}+0.0571 x_{2}+0.0651 x_{3}+0.0587 x_{4}+0.0514 x_{5}+0.0080 x_{6}
$$

\section{CRAR constraint}

Bank management usually allot proportions of sum total asset amount, $Q$, to riskless assets; in this case fixed assets and non-interest earning assets, before making any investment. In this regard, we assume bank management allocate $€ 480000$ to fixed assets and $€ 420000$ to non-interest earning assets.Therefore, we denote total amount for investment in loans $(\zeta)$ and treasury bill $\left(\xi_{1}\right)$ as $A=€ 600000$. We employ capital to risk (weighted) assets ratio (CRAR) proposed by Basel III as the stipulated regulation requirement. The minimum total capital requirement is $8 \%$. Basel III introduced two additional capital buffers; capital conservation buffer of $2.5 \%$ and countercyclical buffer of 0 to $2.5 \%$. For the purpose of this study, we assume a total capital requirement ratio, $\lambda$, of $11 \%$ and a safety factor of 0.95 . The constraint based on CRAR is

$$
\begin{aligned}
& \mathbb{P}\left(\frac{A\left(\zeta^{T} x+\xi_{1} x_{6}\right)+900000-1192000}{A\left(0.2 \zeta_{1} x_{1}+0.5 \zeta_{2} x_{2}+\ldots+0.75 \zeta_{5} x_{5}\right)} \geq 0.11\right) \geq 0.95 \\
& \mathbb{P}\left\{y^{0}(x)+y(x)^{T} \zeta \leq 0\right\} \geq 0.95
\end{aligned}
$$

where

$$
\begin{aligned}
& y^{0}(x)=1192000-600000(1+0.0080) x_{6}-480000-420000 \\
& y(x)^{T}=600000\left((0.11 \times 0.2-1) x_{1}+(0.11 \times 0.5-1) x_{2}+\ldots+(0.11 \times 0.75-1) x_{5}\right)
\end{aligned}
$$

Equation (21) is equivalent to

$$
1.4639 \sqrt{\tilde{z} \Gamma \tilde{z}}+\hat{r}^{T} \tilde{z} \leq 0
$$

where

$$
\begin{aligned}
\tilde{z} & =\left[\begin{array}{c}
292000-604800 x_{6} \\
-586800 x_{1} \\
-567000 x_{2} \\
-550500 x_{3} \\
-550500 x_{4} \\
-550500 x_{5}
\end{array}\right] \\
\Gamma & =\left[\begin{array}{cccccc}
0 & 0 & 0 & 0 & 0 & 0 \\
0 & 0.0196 & 0.0039 & 0.0021 & 0.0043 & 0.0027 \\
0 & 0.0039 & 0.0347 & 0.0057 & 0.0085 & 0.0035 \\
0 & 0.0021 & 0.0057 & 0.0232 & 0.0093 & 0.0029 \\
0 & 0.0043 & 0.0085 & 0.0093 & 0.0929 & 0.0145 \\
0 & 0.0027 & 0.0035 & 0.0029 & 0.0145 & 0.0360
\end{array}\right]
\end{aligned}
$$

and

$$
\hat{r}^{T}=\left[\begin{array}{llllll}
1 & 0.9143 & 0.8696 & 0.9247 & 0.6215 & 0.8451
\end{array}\right]
$$




\section{Constraint based on other factors}

With requirements of investment allocations summing up to one, the constraint below holds.

$$
\sum_{k=1}^{6} x_{k}=1
$$

From an investment principle, we set up a constraint of nonnegativity with respect to loan allocations as

$$
x_{1}, \ldots, x_{5} \geq 0
$$

Assuming bank management places an allocation limit ratio of 0.01 on treasury bill as a result of its riskless property, then

$$
x_{6} \geq 0.01
$$

The chance-constrained optimization model is converted into a tractable linear SOCP by combining equations (20) and (23-26).

\section{Results and conclusion}

The modified CreditMetrics method described earlier was coded in Matlab(R2015a). All computations were performed on a MacBook Pro (Intel(R) Core(TM) i7-3615QM CPU @ 2.30GHz, 16GB RAM).

Column 8 of Table 6 displays entries of the optimal weights of loans and treasury bill. The 3-year AAA Commercial and Industrial Loan allocation value of 0.0010 is the least amongst the optimal investment allocation values. This may be attributed to its smaller risk weight and interest rate. We observe that an increment in the total liability leads to higher allocation to the treasury bill and vice versa. This is due to the model guarding against loss at the expense of a higher interest. The optimal investment portfolio interest income is 0.0565 which is obtained by computations made by CVX package via Matlab (R2015a).

To further understand the results of the optimization model, we explore CRAR chance constraint with the utilization of optimal investment allocation ratios and worst credit migration path values of loans. The expected values of year-ahead market value of loans under worst case scenario are assigned to $\zeta$, the optimal allocation proportions to $x$ and $\xi_{1}$ equals 1.008 .

Using the loan values under the worst-credit migration path from Table 7 , the CRAR value of 0.0860 is reported. We take this approach for the purpose of testing the model under worst-case scenario of default. The value of CRAR even under worst case scenario confirms the bank is guaranteed of coping with Basel III minimum total requirement of 0.08 with great likelihood of $95 \%$.

The paper presented a chance-constraint optimization model that guarantees a bank, with treasury bills, fixed assets, non-interest earning assets and loans, to cope with capital requirements of Basel III with a probability of 95\%, whichever the future value of assets will be. The findings of this research work explicitly disclose that the total proportion of CRAR's lower than Basel III minimum capital requirement is less than the risk 
Table 7 Expected value of year-ahead market value of loans under worst case scenario

\begin{tabular}{lll}
\hline Loan type & Worst-credit migration path & Value \\
\hline 3 Year AAA commercial and industrial loan & $A A A \rightarrow C C C \rightarrow C C C \rightarrow D$ & 0.5214 \\
5 Year AA agriculture and farm loan & $A A \rightarrow C C C \rightarrow C C C \rightarrow C C C \rightarrow C C C \rightarrow D$ & 0.5296 \\
2 Year BBB personal loan & $B B B \rightarrow D$ & 0.3798 \\
3 Year B education loan & $B \rightarrow C C C \rightarrow C C C \rightarrow D$ & 0.5380 \\
4 Year A vehicle loan & $A A A \rightarrow C C C \rightarrow C C C \rightarrow C C C \rightarrow D$ & 0.5171 \\
\hline
\end{tabular}

probability of $5 \%$. Therefore, the chance-constrained CRAR optimization model does guarantee banks of meeting capital requirements of Basel III with greater likelihood of $95 \%$ irrespective of changes in forward market value of assets.

\section{Author's contributions}

EFEAM, the corresponding author, conceived, designed the methodology and wrote the paper. LG aided in the numerical experiment and analysis of the results. BY made a significant contribution to the methodological approach, analysis framework and supervised the study. All authors have read and approved the final manuscript.

\section{Acknowledgements}

We thank Yan Danwen and the reviewers for taking time to add their comments and suggestions to this paper. We also thank SpringerPlus for giving us the platform to contribute to literature. We acknowledge support by the National Nature Science Foundation of China $(11571061,71301017)$.

Competing interests

The authors declare that they have no competing interests.

\section{Appendix}

In this "Appendix" we provide details and pseudocodes of the numerical procedure described in "CreditMetrics approach" section.

The first step of our experiment is represented by the simulation of non-default and default paths. The general procedure for implementation are as follows:

Step A Simulation of all non-default and default paths for maturity period $m$.

In this step all non-default and default paths are generated for maturity $M=1, \ldots, m$ years. The output for every $M$ in a non-default path is a matrix of size $7^{m} \times M$ where rows correspond to a path and columns indicate credit rating at the end of the year. All the $m$ default path matrices are stored in a cell array of length $m$. The output for every $M$ in a default path is a matrix of size $7^{(m-1)} \times M$. But unlike non default paths, for default paths with maturity $m$ the possible paths are all paths in all matrices from $M=1, \ldots, m$. The indexing scheme of $A A A \rightarrow 1, A A \rightarrow 2, A \rightarrow 3, B B B \rightarrow 4, B B \rightarrow 5, B \rightarrow 6, C C C \rightarrow 7$ and $D \rightarrow 8$ is used.

The pseudocode is as follows:

1a. set the maturity period $M=1$;

2a. initialize a zero matrix of size $7^{M} \times M$;

3a. convert decimal number $W=0$ to base 7 of length $M$ and store it in the matrix row $R=1$

4a. $\quad$ set $W=W+1$ and $R=R+1$;

5a. if $W<7^{m}$, repeat steps $3 \mathrm{a}$ and $4 \mathrm{a}$;

6a. add 1 to all the elements in the matrix;

7a. store the resultant matrix in cell array $\operatorname{mig} N\{M\}$, the non-default migration path; 
8a. store 8 in the $1 \times 1$ default path matrix (direct default in first year);

9a. add it to cell array $\operatorname{mig} D\{M\}$, default migration path;

10a. get the matrix from $\operatorname{mig} N\{M-1\}$;

11a. append the matrix with a column of 8's and add to $\operatorname{mig} D\{M\}$;

12a. set $M=M+1$;

13a. if $M<m$, repeat steps 2 a to 13 ;

Step B Calculating discount factors.

This step precomputes and stores discount factors for all transition probabilities for $m=1, \ldots, 5$. The procedure runs as follows:

1b. load forward rates data from Table 3;

2b. append a column of $1 \mathrm{~s}$ in $d$ Factor first column i.e. $d$ Factor $\{1\}=$ ones $(7,1)$;

3b. for every $M=1, \ldots, m$ and for every path for both $m i g D$ and $m i g N$, calculate discount factors using the recurrent relation;

4b. store them in the cell arrays $d F D$ as discount factors for default paths and $d F N$ as discount factors for non-default paths respectively;

Step $C$ Calculating $\zeta_{k t}$ and $P_{k t}$ for non-default paths.

This step computes forward value of a unit capital invested in $k$ th loan with a nondefault credit rating migration path $t$ and its associated migration probability.

1c. for every loan $\mathrm{k}=1, \ldots, \mathrm{K}$ and for every migration path $t=1, \ldots, T$, repeat the following;

2c. load discount factors obtained by step B $(d F N)$;

3c. load interest rates deduced from Table 6, Column 3;

4c. calculate forward value $\zeta_{k t}$ using Eq. (9);

5c. load migration path possibilities obtained from Step A;

6c. calculate $P_{k t}$ using Eq. (11) for non-default migration path;

7c. compute $\zeta_{k t} \cdot P_{k t}$ for non-default migration path;

Step D Calculating $\zeta_{k t d}$ and $P_{k d t}$ for default paths.

This step computes forward value of a unit capital invested in $k$ th loan with a default credit rating migration path $d t$ and its associated migration probability.

1d. for every loan $\mathrm{k}=1, \ldots, \mathrm{K}$ and for every migration path $t=1, \ldots, T$, repeat the following;

2d. load discount factors obtained by step B (dFD);

$3 d$. load recovery rates deduced from Table 2;

4 d. calculate forward value $\zeta_{k d t}$ using Eq. (9);

5d. load migration path possibilities obtained from Step A;

6d. calculate $P_{k d t}$ using Eq. (12) for default migration path;

$7 \mathrm{~d}$. compute $\zeta_{k d t} \cdot P_{k d t}$ for default migration path; 
Step E Estimating $E\left(\zeta_{k} \mid \zeta_{k} \leq b\right)$ and $\operatorname{Var}\left(\zeta_{k} \mid \zeta_{k} \leq b\right)$

This step estimates expected forward loan value and variance of unit capital invested in $k$ th loan. The steps consist of:

1e. for every loan $\mathrm{k}=1, \ldots, \mathrm{K}$, repeat the following;

2e. sum all $P_{k t} \cdot \zeta_{k t}$ to get $\mu_{k}$;

3e. compute $\sigma_{k}^{2}$ using the computed $\mu_{k}$ as shown in Eq. (14);

4e. use the above information to compute expected forward loan value $E\left(\zeta_{k} \mid \zeta_{k} \leq b\right)$ and variance of unit capital $\operatorname{Var}\left(\zeta_{k} \mid \zeta_{k} \leq b\right)$ from equations (12) and (13) respectively;

Received: 23 January 2016 Accepted: 5 April 2016

Published online: 22 April 2016

\section{References}

Abaffy J, Bertocchi M, Dupačová J, Moriggia V, Consigli G (2007) Pricing nondiversifiable credit risk in the corporate Eurobond market. J Bank Finance 31:2233-2263

Alizadeh F, Goldfarb D (2003) Second-order cone programming. Math Program 95:3-51

Altman El (1989) Measuring corporate bond mortality and performance. J Finance 44(4):909-922

Arnold B, Borio C, Ellis L, Moshirian F (2012) Systemic risk, macroprudential policy frameworks, monitoring financial systems and the evolution of capital adequacy. J Bank Finance 36:3125-3132

Asarnow E, Edwards D (1995) Measuring loss on defaulted bank loans: a 24-year study. J Commer Lend 77:11-23

Athanasoglou PP, Brissimis SN, Delis MD (2008) Bank-specific, industry-specific and macroeconomic determinants of bank profitability. J Int Financ Mark Inst Money 18:121-136

Barrera J, Homem-de Mello T, Moreno E, Pagnoncelli BK, Canessa G (2014) Chance-constrained problems and rare events: an importance sampling approach, Preprint available at Optimization Online (http://www.optimization-online.org)

Benz M (2002) The implications of the "new capital adeqaucy framework" for credit risk and capital management in the banking industry. Diplom.de

Berger AN, DeYoung R, Flannery MJ, Lee D, Öztekin O (2008) How do large banking organizations manage their capital ratios? J Financ Serv Res 34:123-149

Bessis J (2015) Risk management in banking. Wiley, New York

Bridges J, Gregory D, Nielsen M, Pezzini S, Radia A, Spaltro M (2014) The impact of capital requirements on bank lending. Bank of England Working Paper

Brusov P, Filatova T, Orekhova N, Eskindarov M (2015) The global causes of the global financial crisis, modern corporate finance, investments and taxation. Springer, Berlin, pp 93-98

Calabrese R, Zenga M (2008) Measuring loan recovery rate: methodology and empirical evidence. Stat Appl 6:193-214

Calabrese R (2014) Predicting bank loan recovery rates with a mixed continuous-discrete model. Appl Stoch Models Bus Ind 30:99-114

Calafiore GC, El Ghaoui L (2006) On distributionally robust chance-constrained linear programs. J Optim Theory Appl 130:1-22

Cannata F, Quagliariello M (2009) The role of Basel II in the subprime financial crisis: guilty or not guilty? CAREFIN Research Paper, 3/09

Carty LV, Lieberman D (1996) Corporate bond defaults and default rates 1938-1995. Moodys Investors Service, Global Credit Res

Charnes A, Cooper WW (1963) Deterministic equivalents for optimizing and satisficing under chance constraints. Oper Res 11:18-39

Choudhry M (2012) The principles of banking. Wiley, New York

Crouhy M, Galai D, Mark R (2010) Risk exposures. Encyclopedia of Quantitative Finance, Wiley Online Library

Delage E, Mannor S (2010) Percentile optimization for Markov decision processes with parameter uncertainty. Oper Res 58:203-213

Erkens DH, Hung M, Matos P (2012) Corporate governance in the 2007-2008 financial crisis: evidence from financial institutions worldwide. J Corp Finance 18:389-411

Flannery MJ (2014) Maintaining adequate bank capital. J Money Credit Bank 46:157-180

Flannery MJ, Rangan KP (2008) What caused the bank capital build-up of the 1990s? Rev Finance 12:391-429

Gropp R, Heider F (2010) The determinants of bank capital structure. Rev Finance 14(4):587-622

Gupton GM, Finger CC, Bhatia M (1997) CreditMetrics: technical document. JP Morgan \& Co, Los Altos

Hasan I, Siddique A, Sun X (2015) Monitoring the invisible hand of market discipline: capital adequacy revisited. J Bank Finance 50:475-492

Jankowitsch R, Nagler F, Subrahmanyam MG (2014) The determinants of recovery rates in the US corporate bond market. J Financ Econ 114:155-177

Khieu HD, Mullineaux DJ, Yi HC (2012) The determinants of bank loan recovery rates. J Bank Finance 36:923-933 
Krug S, Lengnick M, Wohltmann HW (2015) The impact of Basel III on financial (in) stability: an agent-based credit network approach. Quant Finance 15(12):1917-1932

Lee E (2014) Basel III and its new capital requirements, as distinguished from basel II. Bank Law J 131:27-69

Luedtke J (2014) A branch-and-cut decomposition algorithm for solving chance-constrained mathematical programs with finite support. Math Program 146:219-244

Maggioni FRANCESCA, Potra FA, Bertocchi MI, Allevi E (2009) Stochastic second-order cone programming in mobile ad hoc networks. J Optim Theory Appl 143(2):309-328

McNeil AJ, Frey R, Embrechts P (2015) Quantitative risk management: concepts, techniques and tools: concepts, techniques and tools. Princeton University Press, Princeton

Prékopa A (1995) Stochastic programming. Math Appl 324

Rachev ST (ed) (2003) Handbook of heavy tailed distributions in finance: handbooks in finance (vol 1). Elsevier, Amsterdam

Rachev ST, Menn C, Fabozzi FJ (2005) Fat-tailed and skewed asset return distributions: implications for risk management, portfolio selection, and option pricing (vol 139). Wiley, New York

Renault O, Scaillet O (2004) On the way to recovery: a nonparametric bias free estimation of recovery rate densities. J Bank Finance 28:2915-2931

Saunders A, Allen L (2010) Credit risk management in and out of the financial crisis: new approaches to value at risk and other paradigms. Wiley, New York

Schuermann TI (2004) What do we know about loss given default? Working Paper, Federal Reserve Bank of New York. Also in Shimko D (ed) (2006) Credit risk models and management, 2nd edn. Risk Books, London, UK

Standard \& Poor's (2014) 2013 Annual global corporate default study and rating transitions. Retrieved from http://www. maalot.co.il/publications/fts20140324161422. pp 53-54

Szegö GP (2004) Portfolio theory: with application to bank asset management. Academic Press, London

Uryasev S (2000) Introduction to the theory of probabilistic functions and percentiles (value-atrisk). Springer, Berlin

Yang W, Xu H (2016) Distributionally robust chance constraints for non-linear uncertainties. Math Program 155(1-2):231-265

Zymler S, Kuhn D, Rustem B (2013) Distributionally robust joint chance constraints with second-order moment information. Math Program 137:167-198

\section{Submit your manuscript to a SpringerOpen ${ }^{\circ}$ journal and benefit from:}

- Convenient online submission

\section{- Rigorous peer review}

- Immediate publication on acceptance

Open access: articles freely available online

- High visibility within the field

- Retaining the copyright to your article

Submit your next manuscript at $\boldsymbol{\nabla}$ springeropen.com 